\title{
From quality control to TQM, service quality and service sciences: a 30-year review of TQM literature
}

Chi-Kuang Chen, Lidia Reyes, Jens Jörn Dahlgaard and Su Mi Dahlgaard-Park

The self-archived postprint version of this journal article is available at Linköping University Institutional Repository (DiVA):

http://urn.kb.se/resolve?urn=urn:nbn:se:liu:diva-182015

N.B.: When citing this work, cite the original publication.

Chen, C., Reyes, L., Dahlgaard, J. J., Dahlgaard-Park, Su Mi, (2021), From quality control to TQM, service quality and service sciences: a 30-year review of TQM literature, International Journal of Quality and Service Sciences. https://doi.org/10.1108/IJQSS-09-2021-0128

Original publication available at:

https://doi.org/10.1108/IJQSS-09-2021-0128

Copyright: Emerald

http://www.emeraldinsight.com/ 


\title{
From Quality Control to TQM, Service Quality and Service Sciences: A 30-year Review of TQM Literature
}

\author{
Lidia Reyes \\ Postdoctoral, Department of Industrial Engineering and Management, Yuan Ze University, Taiwan \\ lidia.a.reyes@gmail.com/lara@saturn.yzu.edu.tw \\ Jens J. Dahlgaard \\ Professor, Department of Management and Engineering, Linköping University, Sweden \\ jens.jorn.dahlgaard@liu.se \\ Su Mi Dahlgaard-Park \\ Professor, Department of Service Management and Service Studies, Lund University, Sweden \\ su_mi.dahlgaard-park@ism.lu.se \\ Chi-Kuang Chen* \\ Professor, Department of Industrial Engineering and Management, Yuan Ze University, Taiwan \\ *Corresponding author: ieckchen@saturn.yzu.edu.tw \\ 135 Yuan-Tung Road, Chung-Li 320, Taiwan, ROC
}

\begin{abstract}
Purpose

This paper reviews Total Quality Management (TQM) literature in the past three decades to identify the quality related key terms, to analyse their linkage among the identified key terms and their developmental trends.

Design/Methodology/Approach

Bibliometric and statistical methods are used to analyse article titles published in the Total Quality Management \& Business Excellence journal during 1990 to 2019. The current research is based on a search from the ProQuest academic database and the journal's website, resulting in 2,452 articles collected. The VOSviewer and Microsoft Excel were then used for the analyses.

\section{Findings}

52 key terms were extracted from the journal's 2,452 article titles, the top three key terms in terms of occurrences were 'quality', 'total quality management' and 'service quality'. Five themes were then proposed from clustering the 52 key terms: 'frameworks/models', 'essentials/enablers', 'methods/techniques', 'culture/characteristics' and 'effects/results. Trend analyses were also conducted regarding the five themes in an attempt to highlight the patterns of research publications from 1990 to 2019. It's found that the research publications for 'essentials/enablers', 'methods and techniques' and 'effects/results' have steadily increased during the analysis period, while 'frameworks/models' and 'culture/characteristic' have slightly decreased. These insights provide implication for the historical evolution of quality from 'quality control', 'total quality management' and 'service quality', combining with the development of 'service sciences'.

Originality/Value

The paper highlights the concept of quality since its meaning has changed and evolved over time from quality control, total quality management to service quality. And it's emerging in the present and future development of service sciences due to both of TQM and service sciences having the same nature of multidisciplinary background and characteristics. Also we can
\end{abstract}


conclude that quality and service sciences are in fact two sides of the same coin because both of them having the same duality of 'tangible-intangible' and 'physical-virtual' faces which are the important topics that TQM should focus on.

KEYWORDS: Total Quality Management; Business Excellence; Quality; Service Quality; Service Sciences; Bibliometric Analysis

\section{Introduction}

Total Quality management (TQM) has during the past decades evolved to become one of the most widespread management approaches/ strategies for improving products, services and processes, to achieve higher organisational competitiveness. The roots of TQM can be tracked back to the first quarter of the 20th century with quality inspection and quality control. Quality gurus - such as Crosby (1979), Deming (1982, 1986), Feigenbaum (1961), Ishikawa (1985), and Juran (1986) - laid the foundation to evolve TQM from different perspectives, but they did not contribute with any definition of TQM, but rather, TQM 'building blocks.' For example, Feigenbaum (1961) first defined total quality control (TQC) as 'An effective system for integrating quality development, quality maintenance, and quality improvement efforts of the various groups in an organisation to enable production and service at the most economical levels that allow for full customer satisfaction' (p.1, 12). Feigenbaum comments this definition as: 'Since this activity is one of the major responsibilities of management, quality control must be classified as a management tool, along with similar tools such as production control and budget control'.

While Feigenbaum's definition of TQC did not define TQM, it indicates where quality management has moved in its evolution since Shewhart's $(1924,1931)$ pioneering works on statistical control charts. However, in his 1961 book, Feigenbaum named part one of his book "Business Quality Management" a term indicating which direction he at that time wished and expected TQC to move in the future. We know today that he was totally right on that!

The quality gurus named above as well as other researchers and consultants contributed to the same and never ending discussion on how to improve and manage quality to achieve a competitive advantage (Aquilani et al., 2017), but the suggested strategies and methods naturally differed depending on the quality guru's background, experiences and beliefs. It is important to understand that the same variation can be observed today, when experts suggest change programs under 'the TQM label'. Despite these suggested strategies and methods vary depending on the experts' background, experience and beliefs, it's found that the principles are relatively common or stable when comparing different experts' understanding and definitions of TQM.

Dahlgaard, Kristensen \& Kanji (1997) stated that TQM has historically evolved in four stages: quality inspection, quality control, quality assurance, and ultimately TQM. The evolution of quality that leads to TQM allows companies to progressively implement quality standards parallel with satisfying customers' needs and expectations to further create customer delight, which may include joy and surprise (Yang, 2017). Adopting, adapting and implementing TQM principles permits an organisation to benefit from decreasing the costs of poor quality-in terms of defects, failures, complaints and waste-while simultaneously attaining customers' and stakeholders' satisfaction (Dahlgaard-Park, 2015, p. 808). These features and achievements define TQM as a multidimensional, integrated management theory that includes components from different areas demonstrated to be effective.

To successfully implement the TQM management philosophy, companies must discover ways to compete; specifically, they must demand continuous improvement and innovation, be 
able to satisfy their customers and other stakeholders and gain superior performance (Porter, 2011). Additionally, TQM is recognised as essential in other new business paradigms, such as sharing models (Yang et al., 2019), frugal innovation (Radjou \& Prabhu, 2013), and teleworking (Saxunova, 2018). Therefore, Dahlgaard-Park et al. (2018) stated that TQM as an adoptable and adaptable philosophy is now a management theory differentiated from others by three core values or principles: 'adding value for customers', 'creating a sustainable future' and 'harnessing creativity and innovation'. These principles or core business values remain essential to those new business paradigms because they affect how organisations are established and managed. Indeed, traditional TQM principles do not vanish under the guidance of 'process quality' or 'management by facts' in the modern digital technology era, but rather, must be interpreted considering the context and the adoptable and adaptable capability of TQM. More specifically, the implementation of TQM in the current and future era has to be adjusted or even further innovated along with the changes of customer value and the external environment.

Despite the great achievements from implementing the TQM approach, Dahlgaard-Park et al. (2013) discovered that the total number of articles examining TQM has decreased since the mid-1990s. The authors inferred that TQM has matured as a research subject, with research shifting from the TQM principles to the methods, tools, techniques and core values needed to build a quality excellence culture. The decreased number of articles on TQM might indicate that TQM has lost its appeal which some researchers also concluded in that period; however, we know today that the TQM research umbrella at that moment did not consider all its many components or building blocks which gradually has been identified and researched during the following period until today (Dahlgaard et al., 2019) - a process we believe will continue in the future.

The present paper aims to examine TQM as a whole and identify the key terms that represent its research over the last 30 years (1990 to 2019). We further cluster key terms to identify and propose major themes, conduct trend analyses, and summarise the primary intellectual structure of knowledge, which may inspire alternative future research directions and future development of quality.

The remainder of this paper is structured as follows. Section 2 describes research data, methods and procedures. Section 3 provides analyses and results. Section 4 presents discussions and implications. Finally, section 5 summarizes contribution and suggests for the future research.

\section{Research Data, Methods and Procedures}

Several research journals within management, engineering and public administration have published TQM-related research during the focused research period (1990 - 2019); Total Quality Management and Business Excellence (hereafter ' $T Q M \& B E$ ') is chosen as the main source for collecting and analysing research data because of comparing to the other related journals, this journal covers the whole research period and has been dedicated exclusively to stimulate thought and research in all aspects of TQM (Kanji, 1990). The journal was originally named Total Quality Management (1990-2002), and changed to Total Quality Management and Business Excellence $(T Q M \& B E)$ in 2003.

In spite that the analyses conducted in this research focus on $T Q M \& B E$ journal, in discussion and conclusion sections, we combine the findings from the bibliometric analyses conducted in this research with a further investigation of the other research journals and books such as IJQSS (International Journal of Quality and Service Sciences) and Dahlgaard-Park \& Dahlgaard (2021): 'Key Challenges and Opportunities for Quality, Sustainability and Innovation 
in the Fourth Industrial Revolution'. By doing so we intend to come up with the present and future development of TQM from the findings of TQM\&BE journal and especially clarify new identified research trends such as 'quality and service sciences', 'quality management and sustainability' and 'quality management in the 4th industrial revolution'.

\subsection{Research Data Source and Collection}

ProQuest's ABI/INFORM academic database and the TQM\&BE journal's official website were used to retrieve article titles to explore the key terms. Based on the search done through ABI/INFORM database, 2,162 items were identified from 1993 to 2020, with 1,527 items from $T Q M \& B E$, and 635 registered under the previous journal's name. However, very few items (61) were found from 1993 to 1997, and thus, we decided to collect article titles from the journal's official website (https://www.tandfonline.com/toc/ctqm20/current) to obtain complete data, since the journal was founded in 1990. This website presents all volume and issue numbers, publication years, abstracts, and article titles available to the public.

Consequently, 2,422 articles and their publication years were collected from 1990 to the first quarter of 2020 from the journal's official website, excluding editorials, erratum, obituaries, books, and video reviews. We then combined both databases - the journal's official website and ProQuest - in a 'data fusion' process, and excluded repeated items ('data cleaning'). A total of 2,452 articles were collected from 1990 to the first quarter of 2020 (see Figure 1).

The number of articles published in each year can be seen on the top of each bar of Figure 1. According to this figure, the highest number of article publications was in 1998 with 121 publications, representing 5\% of all articles. Moreover, the lowest number of article publications occurred in 1991 and 1992 with 29 publications, representing 1.2\% of all articles.

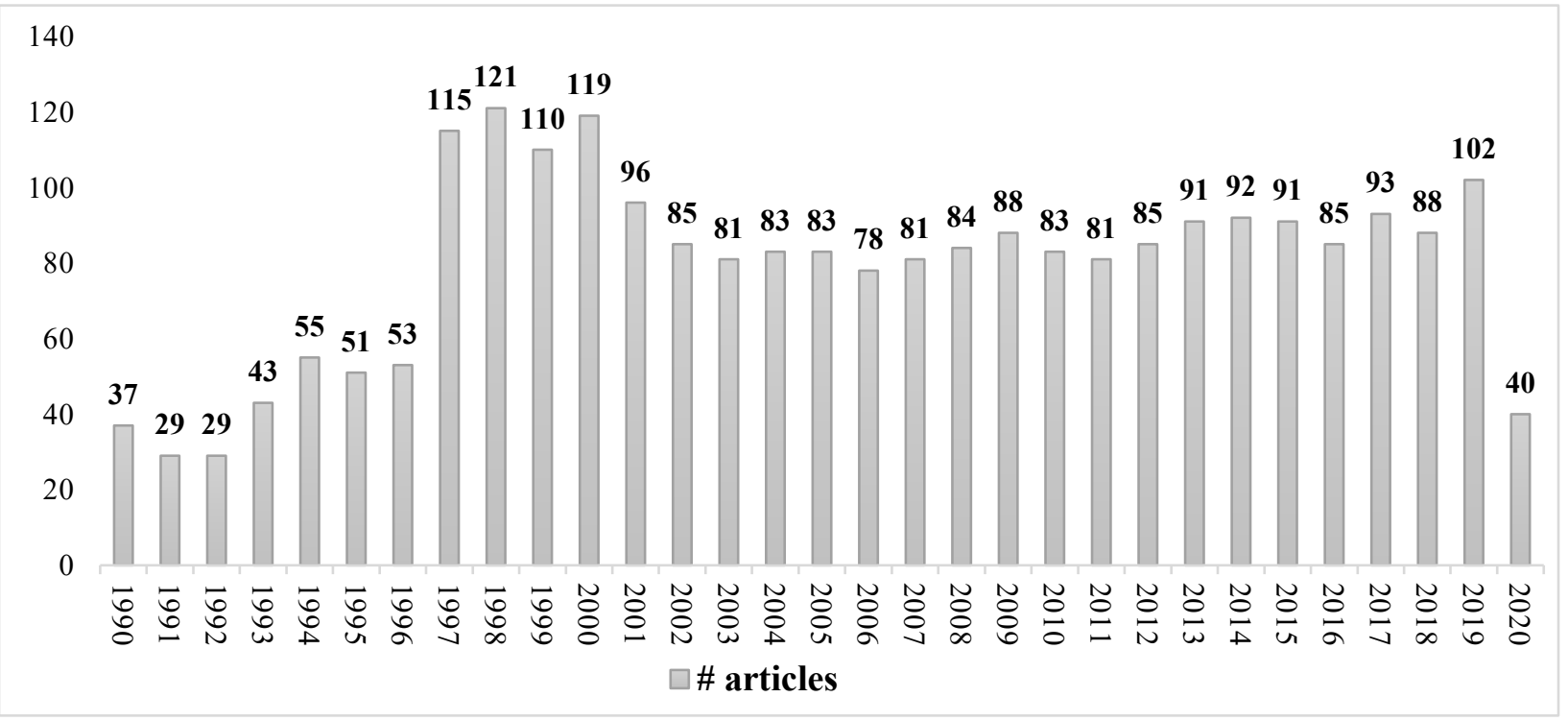

Figure 1. Total number of publications collected after data fusion and cleaning

(Source: Data collected from the $T Q M \& B E$ official website on April 8 and 9, 2020, and from ProQuest's ABI/INFORM database on April 17, 2020)

\subsection{Research Methods and Procedures}


This research used bibliometric methods as a systematic approach. Bibliometrics refers to the 'application of mathematical and statistical methods to books, articles, and other media of communications' (Pritchard, 1969). The VOSviewer software program was used as an analytic tool to identify the key terms used in the 2,542 article titles and to create a bibliometric map. The VOS concept, or 'visualisation of similarities', was developed by Van Eck and Waltman (2010, 2013). The program itself is freely available online (http://www.vosviewer.com) to the research community, and takes a distance-based approach to construct a network/density visualisation map based on the occurrence and co-occurrence data of those key terms extracted from the collected article titles. The terms of the bibliometric method in the VOS viewer program are described below.

a) Occurrence: the number of times a key term occurs in the database;

b) Co-occurrence: the number of times a key term occurs with another key term in the same article title in the database;

c) Link: the connection between two key terms;

d) Links: the number of key terms connected to a specific key term;

e) Link strength: the total number of links connecting a specific key term to its linked key terms;

f) Network/density visualisation map: A map is created by taking a distance-based approach in terms of the number of occurrences and co-occurrence data.

The research study was conducted to follow the following five-step procedure: 1. 'data preparation', 2. 'extracting key terms', 3. 'clustering key terms into themes', 4. 'trend analysis', and 5. 'research findings'. Figure 2 illustrates the research procedures and explains each step.

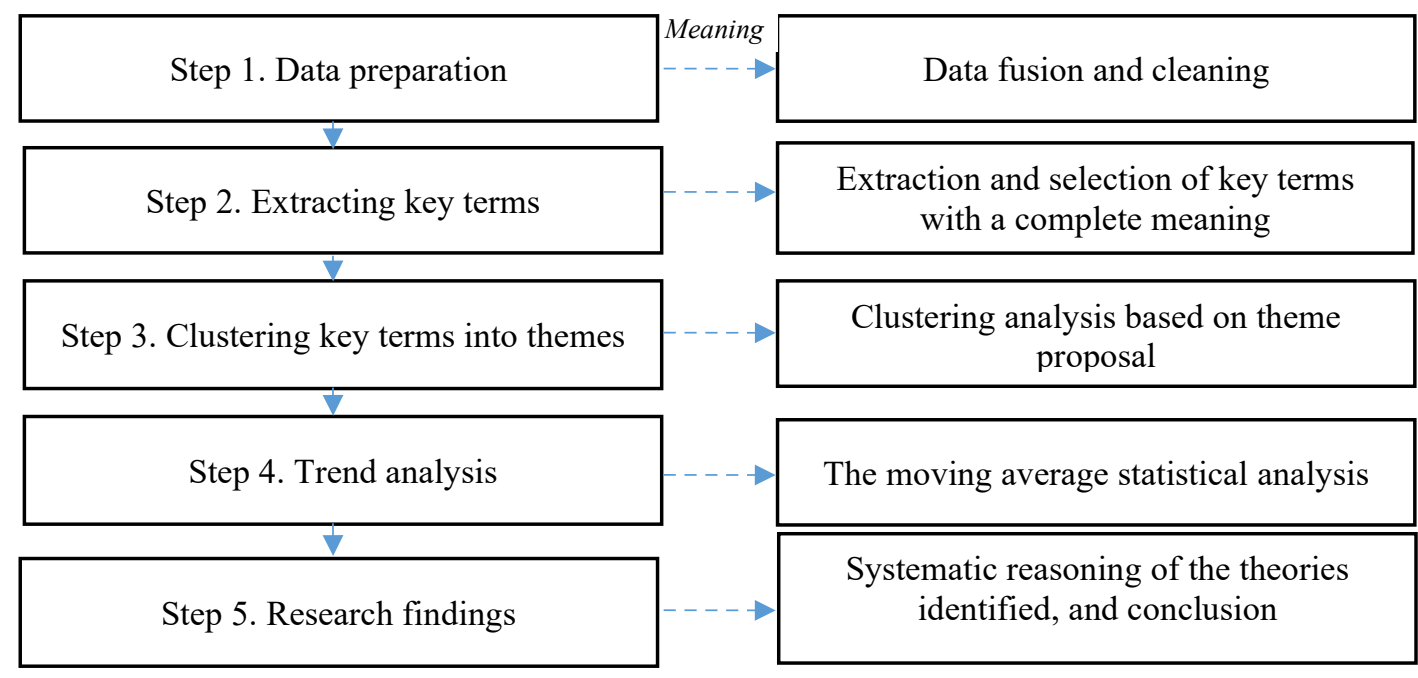

Figure 2. Research procedures

\section{Step 1: Data preparation}

The article titles and their publication year were exported from the $T Q M \& B E$ journal's official website and the ABI/INFORM academic database in an Excel file. In order to make the data analysed accurately, both databases were first fused by using article titles and the published year. Second, the data cleaning involved removing repetitive records from the Excel file. A further revision occurred due to an inconsistency in the article titles, as some are written using capital 
letters or specific signs, such as like '-' or ' $\&$ ' instead of 'and', which create differing records although they are the same article titles. Hence, 2,452 article titles were collected. Figure 1 displays the total number of article titles to be analysed.

\section{Step 2: Extracting key terms}

The second step is the key term extraction using the VOSviewer program, which follows a natural language-processing algorithm to include terms in the analysis with a minimum of 10 occurrences. The minimum criterion of 10 was applied because the key term selection occurred by excluding those terms with only a few occurrences. We also excluded general terms that provide little information, such as 'empirical research', 'study', 'role' and 'point', etc.

\section{Step 3: Clustering key terms into themes}

The third step involves clustering the extracted key terms into themes, in which each theme contains the key terms that are similar to each other and belong to a particular category. The clustering strategy comprehensively explains the main subject of each theme.

\section{Step 4: Trend analysis}

The fourth step is a trend analysis that attempts to highlight and explain the publication pattern of the key terms contained in each theme during the analysis period (1990 to 2019). A movingaverage statistical analysis of the time series is used to identify the trends.

\section{Step 5: Research findings}

The last step involves explaining the research findings based on the data collected, the key terms identified, the theme proposed, and the major intellectual structure implicated through the content analysis.

\section{Results of Analyses}

\subsection{Statistics of The Key Terms}

After collecting the article titles, we identified the key terms that best capture the $T Q M \& B E$ journal's intellectual structure through the VOSviewer software as an analytic tool, which provides an automatic term-identification approach. This program follows a natural languageprocessing technique to identify the key terms in the titles of all articles in the Excel file, with 4,572 terms extracted from 2,452 article titles. Among these, 116 met or exceeded the 10occurrence threshold, and 52 terms were complete noun phrases (Table 1). A noun phrase is a sequence of words in which the last word in the sequence is a noun, and the other word is either a noun or an adjective. For instance, 'service quality', 'customer loyalty', or such terms as 'leadership' and 'innovation' offer information regarding the $T Q M \& B E$ journal's publishing topics.

Table 1 also displays the 52 key terms' number of occurrences, links, and link strength. The VOSviewer's manual indicates that each link's strength is represented by a numerical value. The link strength in this table reveals the number of articles in which two key terms occur together; the higher the value, the stronger the link (Van Eck \& Waltman, 2010 \& 2013). For example, the key term 'quality' has 263 occurrences, 30 links and 116 link strength, which means 30 key terms are linked with 'quality', and the total number of links among the 30 key terms are 116. It has higher link strength than the key term 'total quality management' which is linked with 27 key terms and 57 link strength only. The three key terms (TQM, TQM implementation and QFD) placed in the parenthesis are the same with their non-abbreviated key terms but they are treated as the different words based on the natural language-processing algorithm in the VOSviewer analysis. 
The VOSviewer program takes a distance-based approach to visualising bibliometric networks (Van Eck \& Waltman, 2010 \& 2013). Two key terms' relationship in terms of their link strength is demonstrated by their distance in the visualisation map (Figure 3); the stronger the relationship, the closer the terms' proximity. As we can see from Figure 3, the key terms of 'performance', 'TQM' and 'financial performance' are very close to 'Total Quality Management', which indicate those key terms have high link strength one another.

Table 1. Summary of key terms and themes

\begin{tabular}{|c|c|c|c|c|}
\hline Theme & Key Terms & Occurrences & Links & Link Strength \\
\hline \multirow{12}{*}{$\begin{array}{c}\text { TQM/BE } \\
\text { Frameworks/Models } \\
\text { (14 key terms })\end{array}$} & - Quality & 263 & 30 & 116 \\
\hline & - Total Quality Management (TQM) & $175(72)$ & $27(25)$ & $57(49)$ \\
\hline & - ISO & 98 & 24 & 43 \\
\hline & - Quality management & 94 & 22 & 39 \\
\hline & - Excellence & 63 & 19 & 30 \\
\hline & - Business excellence & 59 & 21 & 34 \\
\hline & - Quality management practices & 35 & 8 & 15 \\
\hline & - Quality management systems & 17 & 5 & 7 \\
\hline & $\begin{array}{l}\text { - Total quality management (TQM) } \\
\text { implementation }\end{array}$ & $14(13)$ & $2(3)$ & $2(5)$ \\
\hline & - EFQM excellence model & 12 & 6 & 8 \\
\hline & - EFQM model & 10 & 4 & 4 \\
\hline & - Total quality & 10 & 1 & 1 \\
\hline \multirow{10}{*}{$\begin{array}{c}\text { TQM/BE } \\
\text { Essentials/Enablers } \\
\text { (10 key terms })\end{array}$} & - Process & 63 & 23 & 45 \\
\hline & - Innovation & 52 & 17 & 41 \\
\hline & - Strategy & 49 & 16 & 33 \\
\hline & - Customer & 33 & 13 & 23 \\
\hline & - Leadership & 29 & 11 & 23 \\
\hline & - Product & 19 & 12 & 18 \\
\hline & - Service & 83 & 23 & 70 \\
\hline & - Quality cost & 16 & 3 & 3 \\
\hline & - Business process & 13 & 3 & 4 \\
\hline & - Knowledge management & 13 & 9 & 12 \\
\hline \multirow{6}{*}{$\begin{array}{c}\text { TQM/BE } \\
\text { Methods/Techniques } \\
\text { (7 key terms) }\end{array}$} & - Sigma & 45 & 20 & 40 \\
\hline & - Lean & 23 & 8 & 23 \\
\hline & - Quality function deployment (QFD) & $22(14)$ & $9(7)$ & $11(9)$ \\
\hline & - Kano model & 15 & 6 & 11 \\
\hline & - Benchmarking & 14 & 3 & 3 \\
\hline & - SERVQUAL & 11 & 9 & 14 \\
\hline \multirow{6}{*}{$\begin{array}{c}\text { TQM/BE } \\
\text { Culture/Characteristic } \\
(6 \mathrm{key} \text { terms })\end{array}$} & - Improvement & 45 & 18 & 29 \\
\hline & - Change & 32 & 13 & 23 \\
\hline & - Integration & 25 & 13 & 20 \\
\hline & - Continuous improvement & 23 & 14 & 15 \\
\hline & - Quality improvement & 21 & 5 & 5 \\
\hline & - Quality culture & 14 & 6 & 6 \\
\hline \multirow{11}{*}{$\begin{array}{l}\text { TQM/BE } \\
\text { Effects/Results } \\
\text { (15 key terms) }\end{array}$} & - Service quality & 121 & 18 & 67 \\
\hline & - Performance & 118 & 27 & 83 \\
\hline & - Customer satisfaction & 77 & 20 & 51 \\
\hline & - Satisfaction & 56 & 12 & 42 \\
\hline & - Loyalty & 33 & 8 & 33 \\
\hline & - Measurement & 33 & 17 & 19 \\
\hline & - Effectiveness & 24 & 13 & 21 \\
\hline & - Assessment & 29 & 17 & 21 \\
\hline & - Self-assessment & 18 & 7 & 9 \\
\hline & - Customer loyalty & 15 & 4 & 14 \\
\hline & - Financial performance & 15 & 12 & 18 \\
\hline
\end{tabular}




\begin{tabular}{|l|l|c|c|c|}
\hline & - Organisational performance & 14 & 8 & 12 \\
\hline - Business performance & 12 & 9 & 9 \\
\hline - Performance measurement & 12 & 4 & 4 \\
\hline - Organisational learning & 10 & 9 & 12 \\
\hline
\end{tabular}

Source: The authors, based on $T Q M \& B E$ website data and VOSviewer analysis

Table 1 provides the top three key terms as research hotspots for $T Q M \& B E$ in the past 30 years: 'quality', 'total quality management', and 'service quality'. Additionally, the relevant key terms in the $T Q M \& B E$ field are clustered by the authors as themes. Five themes were proposed from the 52 key terms: 'TQM/BE frameworks/models' (14 key terms), 'TQM/BE essentials/enablers' (10 key terms), 'TQM/BE methods/techniques' (7 key terms), 'TQM/BE culture/characteristics' (6 key terms) and 'TQM/BE effects/results' (15 key terms). Section 3.2 presents an advanced analysis of the top three key terms and the five themes.

Figure 3 presents a visual density map of the key terms, which reveals a clearly structured field based on the links and link strength that connect all the key terms. Each point in the map has a colour that indicates the density at that point, and these colours range from blue to green to yellow. The larger the number of terms in the neighbourhood of a point and the higher the occurrences of the neighbouring items, the closer the point's colour is to yellow.

For instance, the terms' density is highlighted around 'quality', 'total quality management', and 'service quality', which are the terms that most often occur. This figure displays 31 of the 52 key terms, which means that the structure of $T Q M \& B E$ for the last 30 years has focussed on these topics. Further, their proximity demonstrates the fact that they are connected. For instance, 'total quality management', 'TQM', 'performance', and 'financial performance' are denoted at the middle left of this figure; 'quality', 'improvement', 'strategy' and the 'customer' are at the middle; and 'service quality' and 'customer satisfaction' are displayed at the middle right.

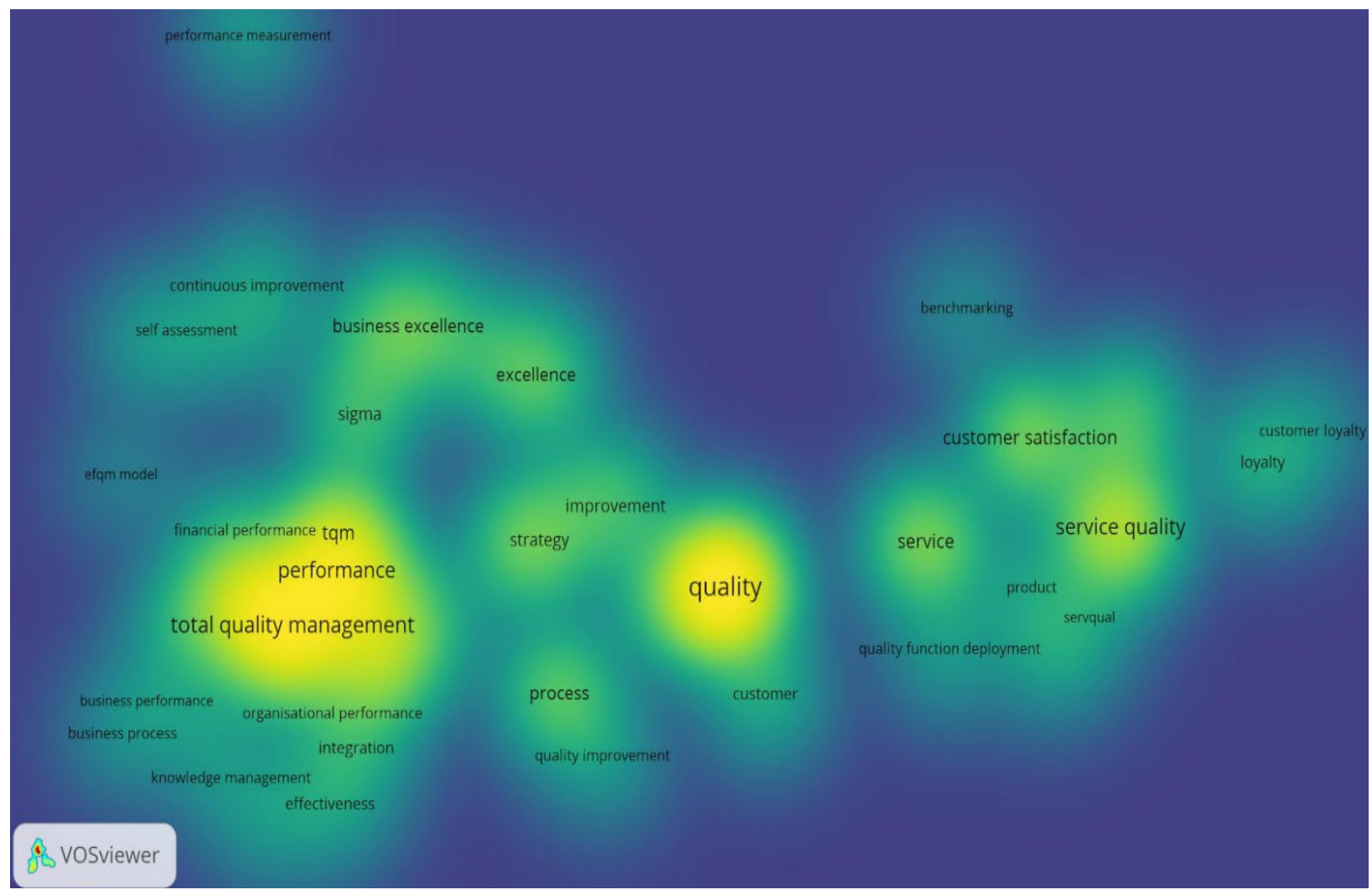


Figure 3. Density visualisation map of key terms

We also observe some of the less prominent key terms, such as 'organisational/business performance', 'business process', 'integration', and 'knowledge management' at the lower left; 'excellence', 'Six Sigma', 'process' and 'quality improvement' in the middle; and 'service', 'product', 'SERVQUAL', 'quality function deployment' (QFD) and 'benchmarking', 'loyalty', and 'customer loyalty' at the middle right.

\subsection{Analyses of The Three Key Terms and Five Themes}

\subsubsection{The top three key terms and their links}

First, we present network visualisation maps for the top three key terms, and specifically, the key terms connected to 'quality', 'total quality management' and 'service quality'.

The 'quality' key term occurs mostly, with 263 occurrences; among these, 30 links and 116 link strengths exist in connection with other key terms. The co-occurrences of these key terms are as follows: 'performance' (15), 'service' (11), 'innovation' (8), 'process' (8), 'customer' (7), 'satisfaction' (7), 'service quality' (6), 'customer satisfaction' (5), 'improvement' (5), 'customer loyalty' (4), 'leadership' (4), 'quality management' (3), 'ISO' (3), 'strategy' (3), 'excellence' (3), 'loyalty' (3), 'measurement' (2), 'assessment' (2), 'TQM' (2), 'QFD' (2), 'knowledge management' (2), 'business excellence' (2), 'effectiveness' (2), 'product' (1), 'organisational performance' (1), 'quality management system' (1), 'quality management practice' (1), 'total quality management' (1), 'financial performance' (1) and 'organisational learning' (1). Based on proximity, the 'assessment', 'customer', 'improvement', and the 'process' key terms relate mostly to quality (Figure 4)

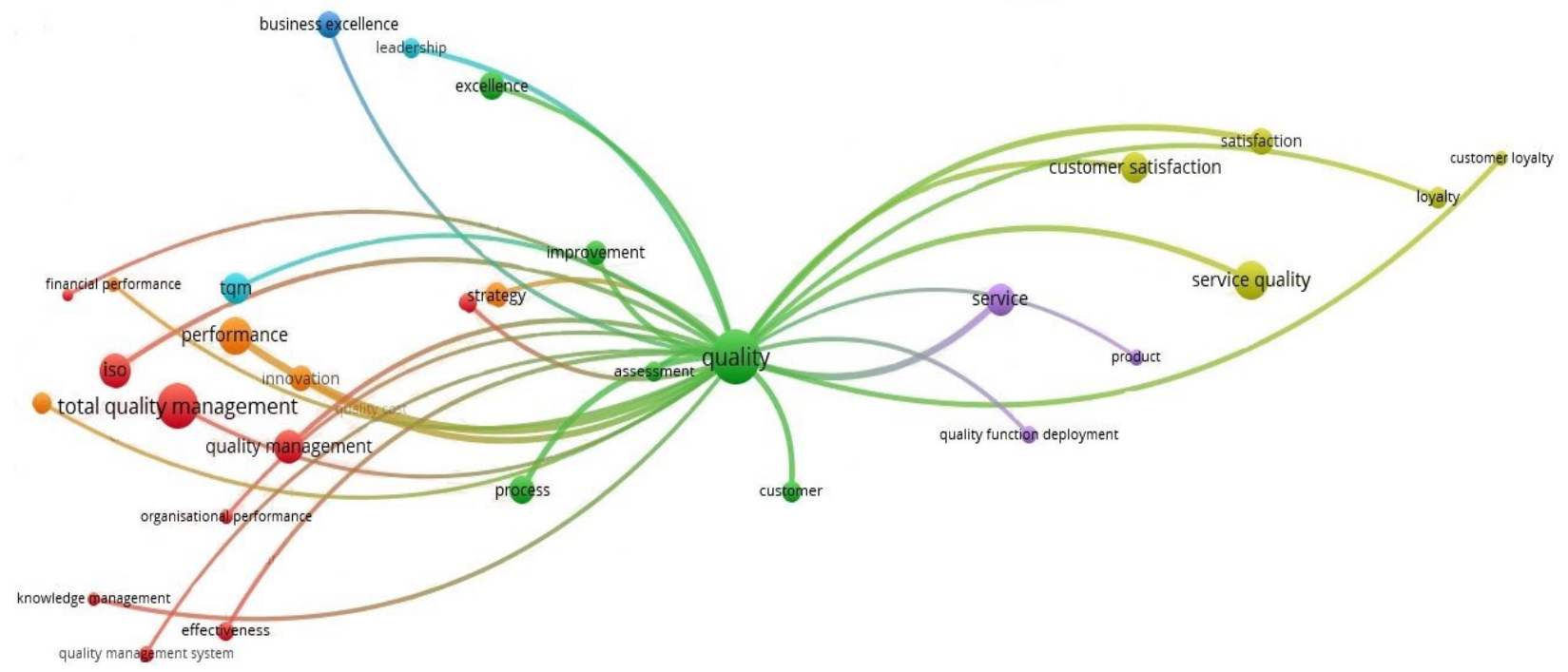

Figure 4. Map of 'quality' key term and its links

The second top key term is 'total quality management' with 175 occurrences; among these, the term has 27 links and 57 link strengths in connection with the other terms. The cooccurrences of the key terms are: 'performance' (6), 'service' (5), 'strategy' (4), 'innovation' (3), 'integration' (3), 'financial performance' (3), 'business excellence' (3), 'ISO' (3), 'change' (3), 'customer satisfaction' (2), 'process' (2), 'business process' (2), 'self-assessment' (2), 
'organisational learning' (2), 'TQM' (2), 'leadership' (1), 'customer' (1), 'measurement' (1), 'quality cost' (1), 'knowledge management' (1), 'quality management system' (1), 'effectiveness' (1), 'continuous improvement' (1), 'service quality' (1), 'quality' (1), 'assessment' (1), and 'business performance' (1). Based on proximity, 'change', 'ISO', 'performance', and 'innovation' are the key terms that relate mostly to total quality management (Figure 5).

The third top key term is 'service quality', with 121 occurrences; among these, 18 links and 67 link strengths exist in connection with the other terms. The co-occurrences of these key terms are: 'satisfaction' (11), 'service' (11), 'loyalty' (7), 'quality' (6), 'customer satisfaction' (9), 'SERVQUAL' (4), 'strategy' (3), 'customer' (3), 'customer loyalty' (3), 'measurement' (2), 'Kano model' (1), 'QFD' (1), 'performance' (1), 'improvement' (1), 'product' (1), 'TQM' (1), 'process' (1), and 'change' (1). Based on proximity, 'satisfaction', 'customer satisfaction', 'SERVQUAL' and the 'Kano model' are the key terms that relate mostly to service quality (Figure 6).
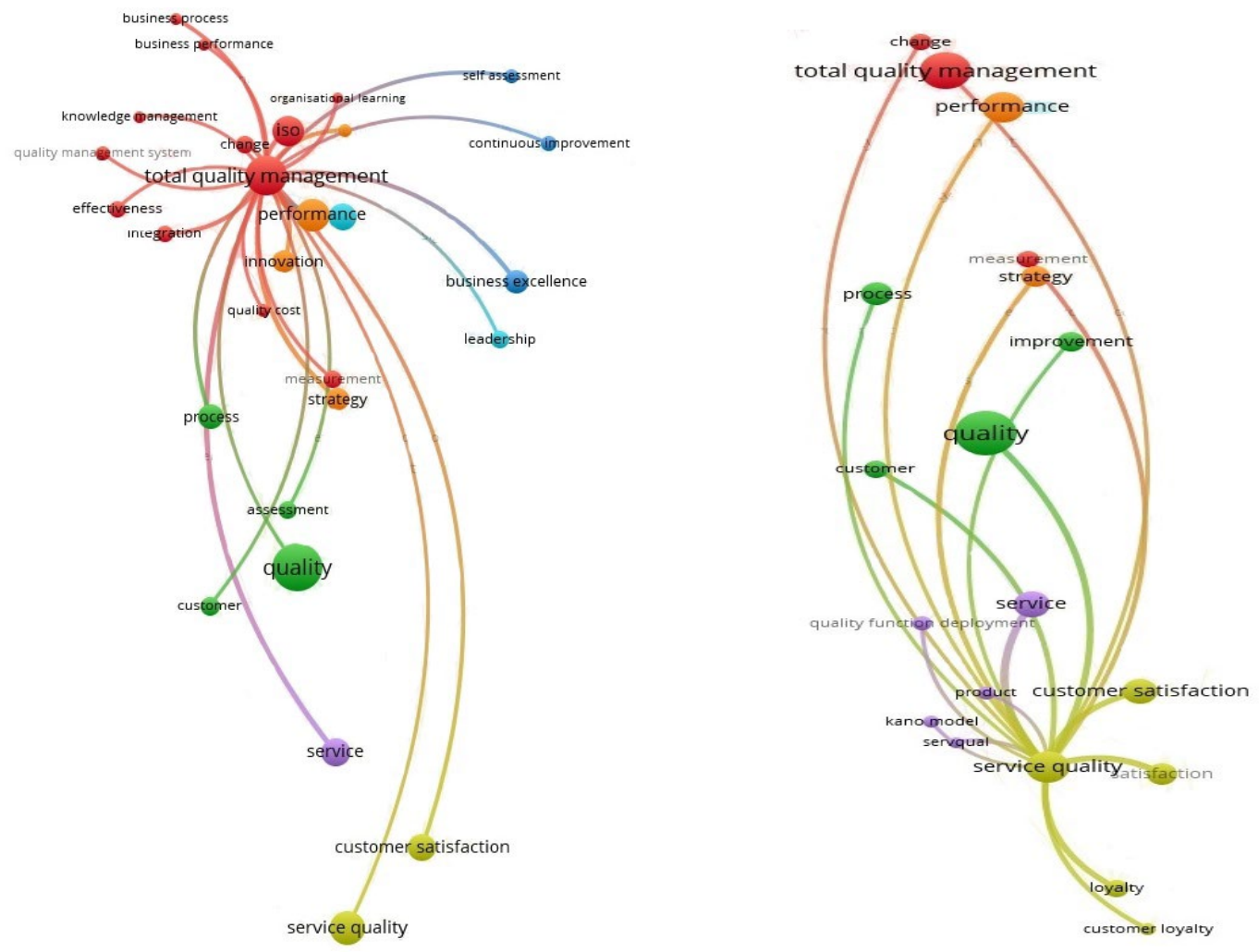

Figure 5. Map of 'TQM' key term and its links

Figure 6. Map of 'service quality' key term and its links

\subsubsection{Theme Analysis}

Next, we present the five themes relative to not only their meaning, but also the order of their key terms' occurrences along the timeline from 1990 to 2019 (Tables 1 and 2).

Theme 1 (TQM/BE frameworks/models) includes the 14 key terms that describe TQM and $\mathrm{BE}$ as a management approach in their principles and main categories. The focus has been on understanding what quality is and the structure needed based on the frameworks and models used 
to implement TQM, with 936 occurrences. 'Quality' occurred most frequently, while 'total quality' along with the EFQM model occurred with the least frequency.

Theme 2 (TQM/BE essentials/enablers) includes 10 key terms that are required to successfully implement TQM (essentials), such as leadership, strategy and innovation; and the key enablers of TQM implementation, such as processes, customers, products and services. The focus has been on services more than products and processes; however, TQM collectively aims to hold all parties involved in the production process of a product or service as accountable for the final product or service's overall quality. This theme has 370 occurrences, with 'service' as the most common term, and 'business process' and 'knowledge management with the fewest occurrences.

Theme 3 (TQM/BE methods/techniques) includes the methods and techniques that promote TQM's importance as well as approaches that can be used to improve overall quality, such as 'SERVQUAL' and 'lean' processes. Moreover, all the included methods and techniques have gained the attention of practitioners and academics, with the Six Sigma and lean approaches as the most popular. This theme had 144 occurrences, with 'Six Sigma' and 'SERVQUAL' occurring the most and least number of occurrences, respectively.

Table 2. The TQM/BE Themes per Year

\begin{tabular}{|c|c|c|c|c|c|}
\hline \multirow[b]{2}{*}{ Year } & \multicolumn{5}{|c|}{ TQM/BE Themes } \\
\hline & $\begin{array}{c}\text { Frameworks/ } \\
\text { Models }\end{array}$ & $\begin{array}{l}\text { Essentials/ } \\
\text { Enablers }\end{array}$ & $\begin{array}{l}\text { Methods/ } \\
\text { Techniques }\end{array}$ & $\begin{array}{c}\text { Culture/ } \\
\text { Characteristics }\end{array}$ & $\begin{array}{l}\text { Effects/ } \\
\text { Results }\end{array}$ \\
\hline 1990 & 10 & 3 & 0 & 1 & 4 \\
\hline 1991 & 14 & 1 & 0 & 8 & 2 \\
\hline 1992 & 14 & 3 & 0 & 3 & 5 \\
\hline 1993 & 20 & 7 & 0 & 10 & 2 \\
\hline 1994 & 17 & 10 & 0 & 10 & 5 \\
\hline 1995 & 27 & 10 & 1 & 6 & 8 \\
\hline 1996 & 23 & 6 & 1 & 11 & 8 \\
\hline 1997 & 41 & 17 & 4 & 26 & 36 \\
\hline 1998 & 43 & 25 & 4 & 17 & 33 \\
\hline 1999 & 52 & 21 & 2 & 12 & 26 \\
\hline 2000 & 44 & 15 & 3 & 19 & 61 \\
\hline 2001 & 37 & 9 & 5 & 10 & 43 \\
\hline 2002 & 45 & 10 & 2 & 8 & 34 \\
\hline 2003 & 27 & 12 & 4 & 10 & 35 \\
\hline 2004 & 38 & 6 & 3 & 11 & 38 \\
\hline 2005 & 41 & 6 & 1 & 11 & 30 \\
\hline 2006 & 42 & 8 & 13 & 2 & 33 \\
\hline 2007 & 29 & 10 & 7 & 10 & 43 \\
\hline 2008 & 31 & 14 & 2 & 6 & 35 \\
\hline 2009 & 24 & 14 & 7 & 17 & 47 \\
\hline 2010 & 32 & 14 & 5 & 3 & 46 \\
\hline 2011 & 37 & 17 & 6 & 6 & 29 \\
\hline 2012 & 27 & 18 & 11 & 5 & 43 \\
\hline 2013 & 23 & 10 & 3 & 9 & 44 \\
\hline 2014 & 35 & 14 & 3 & 11 & 43 \\
\hline 2015 & 35 & 19 & 4 & 4 & 48 \\
\hline 2016 & 25 & 12 & 10 & 11 & 39 \\
\hline 2017 & 39 & 15 & 7 & 14 & 34 \\
\hline 2018 & 25 & 24 & 5 & 4 & 39 \\
\hline
\end{tabular}




\begin{tabular}{|l|l|l|l|l|l|}
\hline 2019 & 30 & 16 & 17 & 9 & 57 \\
\hline
\end{tabular}

Source: The author, based on $T Q M \& B E$ website data and an Excel analysis

Theme 4 (TQM/BE culture/characteristics) highlights a company's quality characteristics, such as its quality culture, quality improvement, and continuous improvement, to successfully implement TQM. Moreover, this implies that a TQM-focused culture requires organisational changes in any company attempting to implement TQM to ensure the fulfilment of customer needs and expectations through quality and continuous improvements. This theme had 160 occurrences, with 'improvement' and 'quality culture' occurring the most and least number of occurrences, respectively.

Theme 5 (TQM/BE effects/results) contains key terms that reflect the effects of implementing TQM, such as 'service quality', 'measurement', 'self-assessment', and 'performance measurement'; and the results obtained while implementing TQM, such as 'enhanced customer satisfaction', 'customer loyalty', and 'organisational learning'. This is the richest theme, as it not only includes 15 key terms that illustrate possible results and effects obtained by implementing TQM and it also incorporates the previous four themes in practice. This theme had 587 occurrences, with 'service quality' and 'organisational learning' occurring the most and least number of occurrences, respectively.

\subsection{Trend Analysis of The Key Terms}

This section presents a time-series analysis of the five themes to examine research trends in $T Q M \& B E$ topics along a timeline. The period starts in 1990 , the year when $T Q M \& B E$ was launched, and ends in 2019. The data used in the analyses include the number of publications collected from the journal and VOSviewer analysis (Tables 1 and 2). A three-year simple moving average (MA) smooths the data to create flowing lines during that period, and offers trend directions for the following year of 2020. The trend demonstrates how the number of publications by theme has evolved since the journal was founded. We also examine the number of studies conducted in terms of the three decades: 1990 to 1999, 2000 to 2009 and 2010 to 2019.

Figure 7 illustrates that the 'TQM/BE frameworks/models' theme has evolved and attracted an increasing audience since 1990, obtaining a 420\% increase from 1990 to $1999(52$ - 10 / 10), and peaked in terms of the number of occurrences in 1999. In the second decade (2000-2009), the theme lost its appeal, as demonstrated by a percentage decrease of $-45 \%(24-44$ / 44). The theme has retained slightly the same level of attention in the last decade, as it has maintained the number of studies but with a percentage decrease of $-6.25 \%(30-32 / 32)$. The blue, linear regression dotted line and black dotted (decade average) in Figure 7 reveals a slight upward trend for the whole period $1990-2020$. 


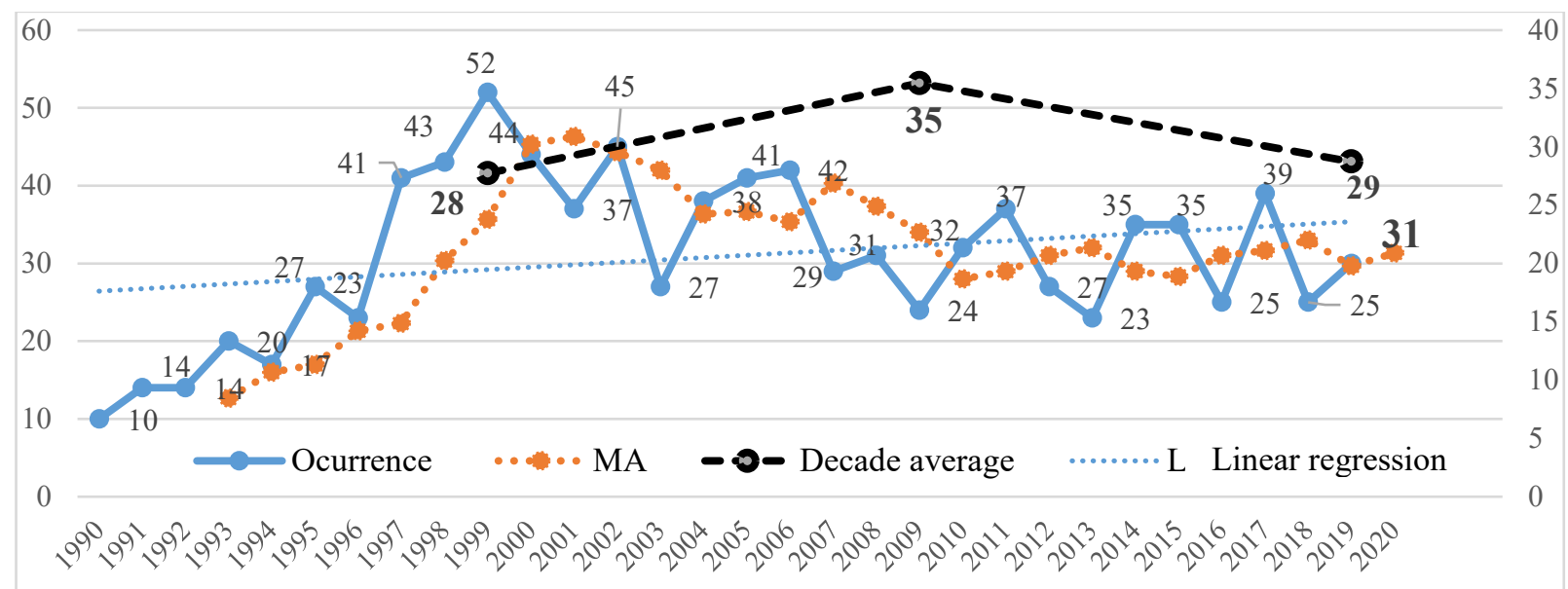

Figure 7. Time-series plot of Theme $1-\mathrm{TQM} / \mathrm{BE}$ frameworks/models

Figure 8 displays the TQM/BE essentials/enablers theme; the essentials and enablers exhibit trends superior to those in Theme 1. The first decade (1990-1999) reveals an increase of 600\% $(21-3 / 3)$. It then peaks in terms of the number of occurrences in 1998. The theme's attractiveness decreased by $-7 \%(15-14 / 14)$ during the second decade, and increased by $14 \%$ $(16-14 / 14)$ in the third. The blue, linear regression dotted line in the figure shows a clear upward trend and the black dotted line shows the same since the second decade.

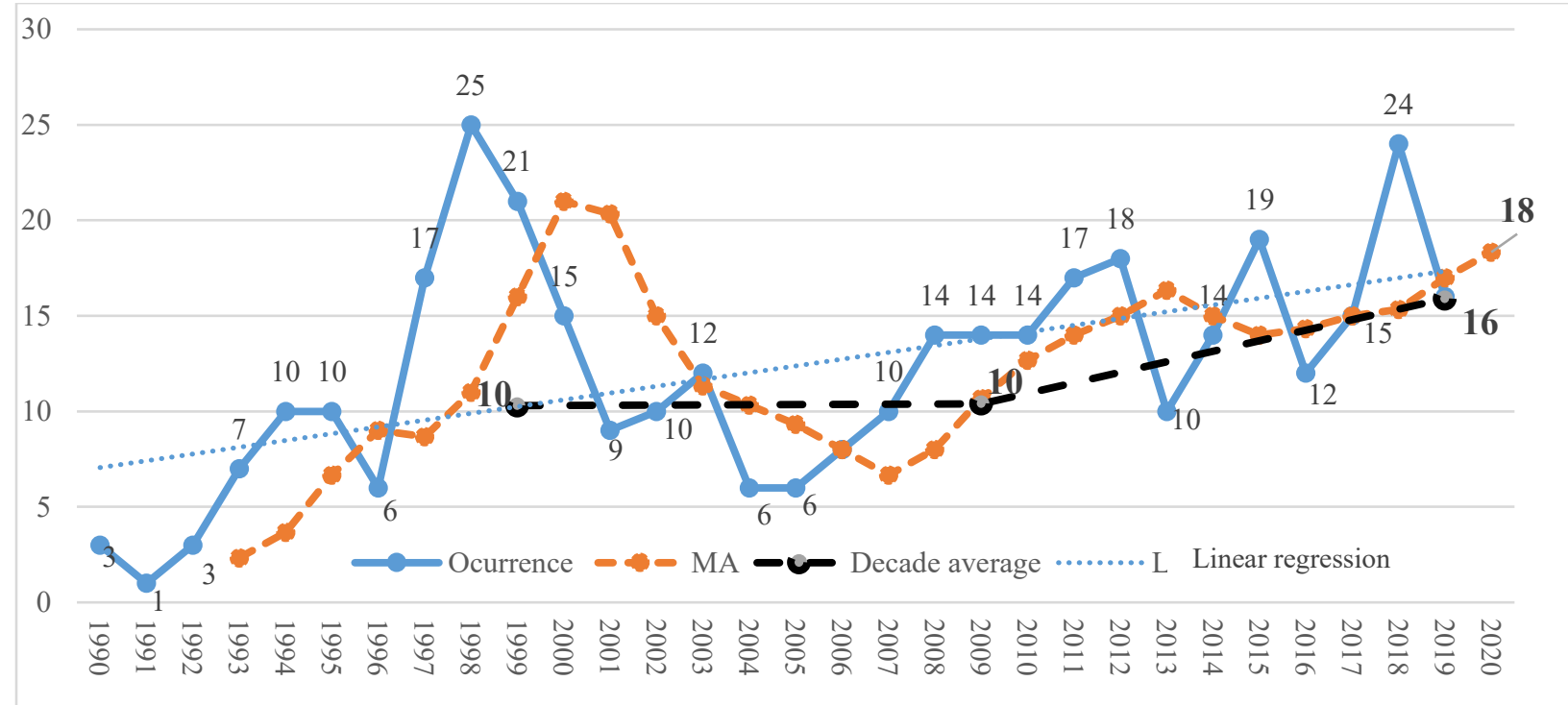

Figure 8. Time-series plot of Theme 2-TQM/BE essentials/enablers

Figure 9 indicates how method- or technique-based research has evolved. Theme 3 exhibited stable numbers of research studies during the first decade, with an increase of $133 \%$ since the second decade. The theme increased by $240 \%$ in the final decade $(17-5 / 5)$. Hence, the pattern has clearly trended upward, as demonstrated by the blue, linear regression dotted line in the figure. 


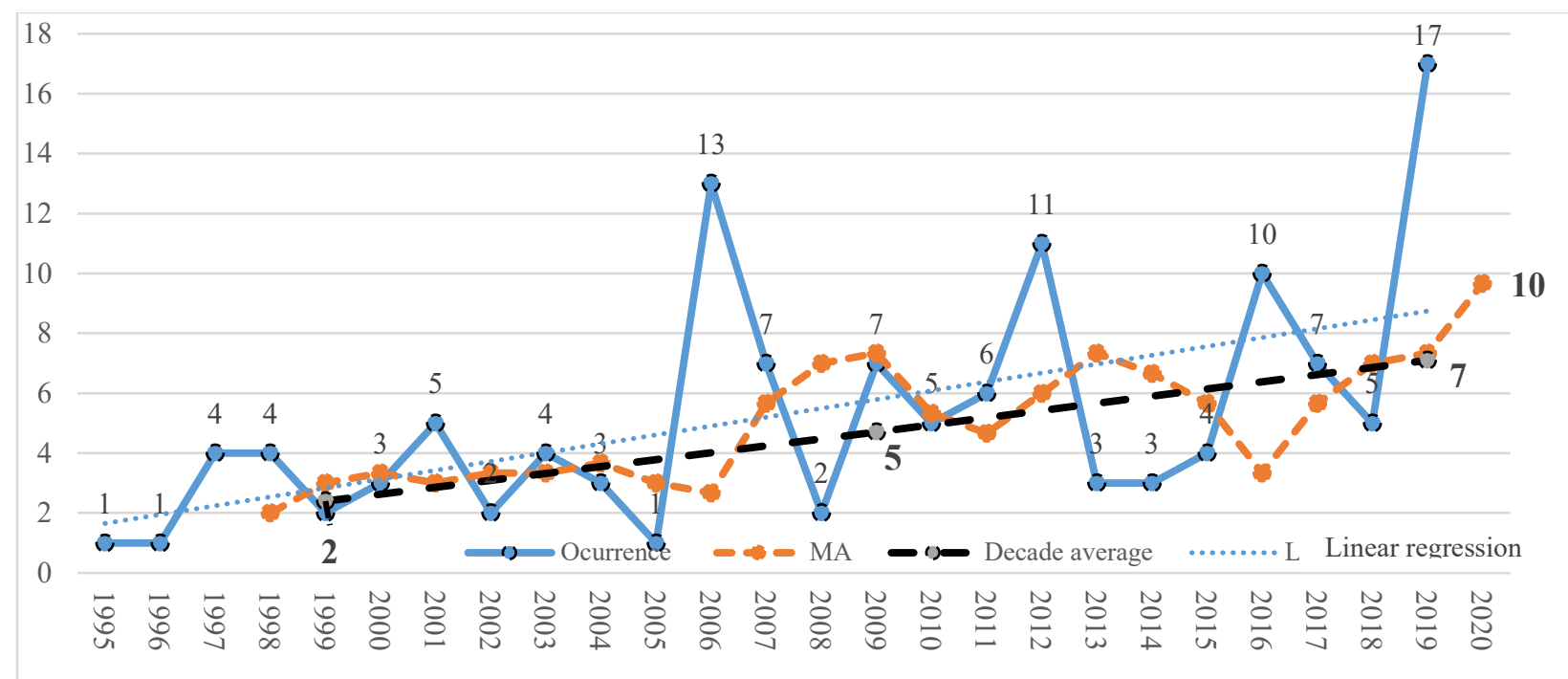

Figure 9. Time-series plot of Theme 3-TQM/BE methods and techniques

Figure 10 illustrates the TQM/BE culture/characteristic theme, with a slightly downward trend. During the first decade, the number of studies increased drastically; in the second decade, it increased by $8 \%(13-12 / 12)$, and in the last decade, the number of studies further decreased. The TQM/BE culture and characteristics theme peaked in 1997, but the number of studies has since decreased, with a slight recovery since 2013 . The blue, linear regression dotted line in the figure reveals a slightly downward trend for the last 10 years.

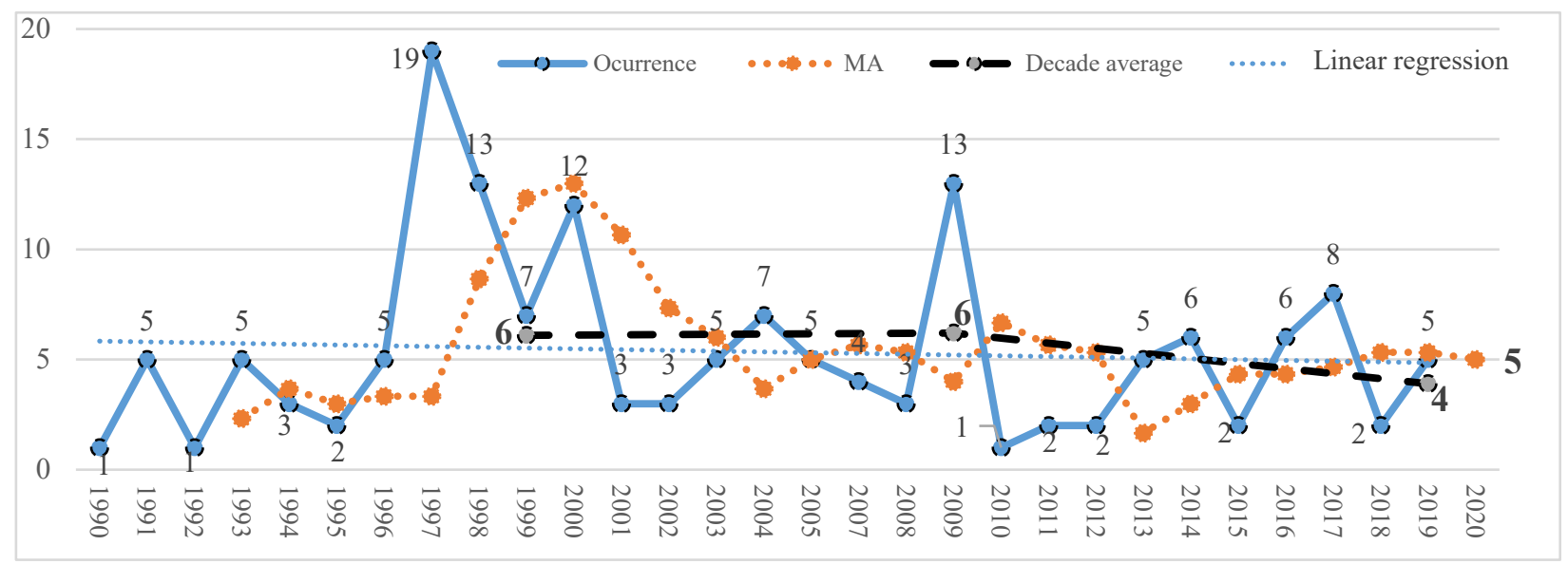

Figure 10. Time-series plot of Theme 4-TQM/BE culture/characteristics 
Figure 11 displays the trends for Theme 5 - the TQM/BE effects/results. Among the five themes, this one exhibits an appealing success over the years. It has the second-highest percentage increase in the first decade of $550 \%(24-4 / 4)$, indicating the attraction to the quality community topics published in this journal, and particularly the evidence regarding the effects and results of implementing TQM. The percentage increased by 3\% in the second decade (33-32/32). Moreover, and with Themes 2, 3 and 4 in the last decade, the number of studies increased by $13 \%(34-30 / 30)$ compared to the previous decade. The blue, linear regression dotted lines in the figure demonstrate a clearly upward trend.

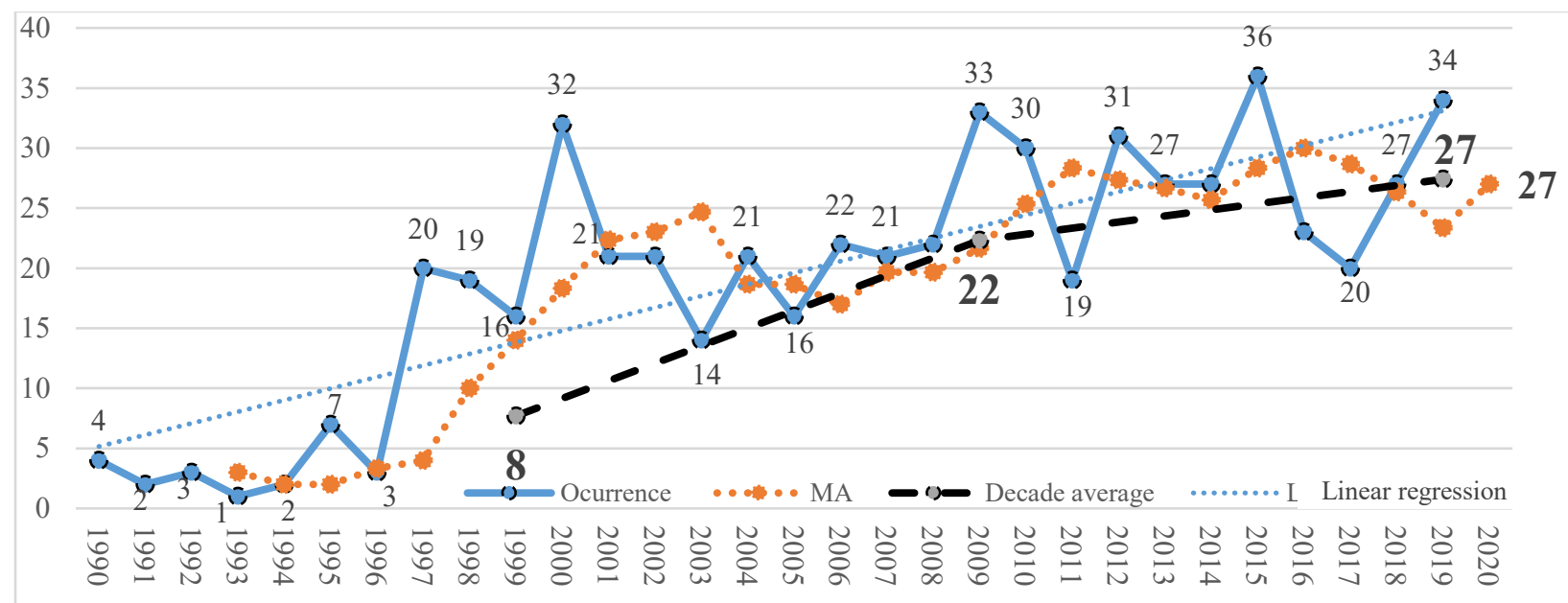

Figure 11. Time-series plot of Theme 5-TQM/BE effects/results

The TQM\&BE publication themes during the three decades should be considered essentials due to their upward evolution, and especially Themes 1,2,3 and 5. The journal's first decade in operation is considered a 'golden period' for TQM, as all the themes attracted researchers' attention, but not as Theme 1. During the journal's first decade and in the beginning of its second decade, research focussed more on explanations of better TQM implementation through different models and approaches and their effects or expected organisational results. In the last part of the first decade, the graphs reveal an upward trend based on the key terms investigated.

In the second decade, dispersion occurred; investigations of the key terms included in Themes 1, 2 and 5-which relate to TQM implementation-became increasingly attractive. These studies became appealing in analyses of the relationships among TQM/BE, customer satisfaction, and loyalty (Themes 1 and 5). Therefore, more empirical research and case studies were necessary to prove TQM/BE's influence on organisations' continuous improvement, as well as their effects on how a business should operate to achieve excellent quality and improve business performance.

In the last decade, Themes 1, 2 and 5 included most of the research published; however, the research community became increasingly attracted to Themes 3 and 4 . The next section further examines these results to identify the intellectual structure that represents the research done over the past three decades.

\section{Discussions and Implications}

In light of the research findings derived from the analyses conducted in Section 3, the following discussion intends to explore the potential implications for this research. First of all, based on the 
top three key terms identified in the past 30 years of quality literature (i.e., 'quality', 'total quality management', and 'service quality'), the relationship among the three key terms along with the historical evolution of quality is further discussed.

It's widely agreed that 'quality', as an independent subject in industrial practice and academic research, started from 'quality control' and 'quality assurance', in the first half of the 20 th century, then 'total quality management' and 'service quality' became popular in the 1980s and after. We thus present this discussion section in terms of three phases of quality development. The first two phases, 'from quality control to total quality management' and 'from total quality management to service quality', are based on a further investigation of the research which are relevant to those key terms, their linkages and the patterns among those key terms. The third phase, 'from service quality to service science', is then served as a projection of the present and future development of quality.

\subsection{From Quality Control to Total Quality Management (TQM)}

Quality Control has a long tradition in industry; it can be tracked back to as early as 1920s with the development of statistical process control charts to control production processes (Shewhart, 1924) and statistical sampling techniques to inspect the finished or semi-finished products (Dodge \& Romig, 1941). Quality inspection and process control has helped companies to reduce errors and produce products in the production efficiently and effectively. Back at the 1950s and from there, practitioners and academics developed further statistical methods, and advanced measuring and test using technology with increasing degrees of automation to produce products of high quality in the factory. The growing complexity in products and services plus the key processes of a company made a broader approach necessary to obtain a better product quality as the result of well-designed and controlled processes.

During the period of time, many concepts, methods and techniques of quality management were developed in Japan beginning in the late 1950s. They were pioneered by American and Japanese quality gurus and evolved significantly as a national preoccupation towards quality control and management. Research in process control and improvement, product development, QFD (Quality Function Development), TQM and business excellence was then developed. As a result of this review research, we found that a lot of interesting research were published under those topics, such as, a collection of quality-related tools and techniques (for instance, Wood, 1997; Kumar et al., 2012, etc.), research examining TQM essentials, principles, theories and concepts to facilitate an understanding of implementation processes (for instance, Black, 1995; Elshennawy et al., 1991; Lammermeyr, 1991; Saunders \& Preston, 1994; Wynne \& Lancaster, 1992; Gremyr \& Elg, 2014, etc.). Subsequently, different empirical studies in the service industries demonstrated the impact on business performance, and thus, the pursuit of business excellence (for instance, Aggarwal \& Zairi, 1997; Lin, 1995; Trenchard \& Dixon, 1999, etc.).

\subsection{From Total Quality Management to Service Quality}

From the last part of the 1980s, TQM had a growing and significant effect on service quality when it gradually became one of the most popular management approaches. Customer orientation became the first principle in TQM that puts the focus on people buying products or services, and the need of discovery and anticipation of customers' requirements and experiences to measure service quality became essential.

Research on service quality has been predominantly conducted since the 1985s. Researchers have been interested in measuring service quality from a customer perspective, based on the two 
critical elements: customer satisfaction and loyalty, such as the research done by Schvaneveldt et al. (1991). Different models, approaches and tools have also been proposed, such as the research done by Donnelly \& Shiu (1999) and the Kano model, a dynamic tool to study potential customer needs. During the period of time, in particular, it is found that much empirical research have been applied to study service quality in different industries and countries from different perspectives by using the Kano model as well as the SERVQUAL method and integrating these tools with Quality Function Deployment (for instance, Tontini, 2007; Sarrico et al., 2013; Nadiye Ozlem \& Arani, 2019, etc.). This research have also collectively been used to explore customers' needs and develop strategies for improving service quality, such as the research done by Sohal (1994). In addition, research has examined the use of these tools not only for designing new products and services, but also evolving beyond simply measuring customers' perceptions to delight the customer (for instance, Alvarez et al., 2012; Kim \& Yoo, 2020, etc.).

\subsection{From Service Quality to Service Science}

Despite the TQM and service quality research were popular in the last part of the 20th century, some criticisms were raised simultaneously. One of the most usual criticism was the measurement of service quality in the theoretical-conceptual and the methodological-operational aspects. For example, the research done by Mauri et al. (2013) argued that the service quality measurement between perceptions and expectations is problematic based on consumers' cognitive process. Other research also criticized that some models remain static, for instance, the service quality measurement scale (SERVQUAL) and the gap model, both were developed by Parasuraman, Zeithaml and Berry (1985). The models focus on analyzing service characteristics and multiple quality dimensions to identify standardized dimensions applicable to all services; however, services possess is a dynamic nature and are extremely hard to be standardized.

In addition, the service sector in the global economy has dominated our life, education, even culture, etc. All of them required a better understanding of users' expectations and demands as a means of driving quality improvements into all not just service but product-oriented organizations (Islam et al., 2015). Vargo \& Lusch (2004) then proposed the service-dominant logic (S-D logic), which is based on the idea that service, defined as the application of knowledge and skills for another's benefit, is the fundamental basis of value creation through the exchange.

Nowadays the S-D logic has been widely accepted by the society of academics and practitioners, because it emphasises on the integration of products and services to offer an intangible value asset for customers (Martensen \& Grønholdt, 2010; Dahlgaard-Park \& Dahlgaard, 2021). Owing to the S-D logic happened along with the progress of information and communication technologies, IBM started to develop a new multidisciplinary science, which is called SSME (Service Science, Management and Engineering). This new science addresses the solutions to unique service sector problems by applying theories and methods from many different disciplines, which include computer science, engineering, marketing, sociology and cognitive science, etc., to keep developing the service research.

Hence, based on this review research, we believe that the future of this new discipline will emerge further into the big family of the quality discipline due to both of TQM and service sciences having the same nature of multidisciplinary background and characteristics. Also we can conclude that quality and service sciences are in fact two sides of the same coin because both 
of them having the same duality of 'tangible-intangible' and 'physical-virtual' face which are the important topics that TQM should focus on.

\section{Conclusions and Suggestions for Future Research}

This paper contributes to the body of knowledge of quality literature in a number of aspects.

First of all, we identified 52 key terms from the past 30 years of publications in the TQM/BE journal and the top three key terms in terms of occurrences which are 'quality', 'total quality management' and 'service quality'.

Second, five themes were identified by clustering the 52 key terms: 'frameworks/models', 'essentials/enablers', 'methods/techniques', 'culture/characteristics' and 'effects/results.

Third, based on the research findings, three phases of quality development in terms of the historical evolution and a future projection have been discussed.

TQM is a strategic management approach that uses quality management tools and techniques to support its implementation, firm effects and best practices. Comparisons and empirical studies have proven TQM's effectiveness, and highlight the importance of establishing customer relationships by studying their perceptions of service quality. Service quality and business excellence have evolved in the last three decades, from research on how to measure service quality and its dimensions, analyse customer perceptions, and gain customer loyalty, to the development of integrated TQM that enhances innovation and organisational learning to achieve excellent performance. Consequently, studies on the impacts of an integrated TQM and its practices in the last decade have been extensively and empirically studied, such as quality, financial, organisational, and operational and innovation performance.

TQM has evolved based on how companies create business models to encounter service quality, customer satisfaction, retention, loyalty, and customer delight, and especially given their use of the Internet, technological advances and business alliances.

However, TQM may assume different nuances of interest depending on how the themes are combined. The final goals remain to continuously improve and to add value for the customer, to create a sustainable future, and to harness people's creativity to generate innovation while transforming the organisation and achieve financial, organisational, operational and business performance results considering the new environment of business: physical and virtual world systems.

Our final conclusion and projection based on this research is that TQM during the previous 30 years has become a new management theory (Dahlgaard-Park et al, 2018) which may become the leading management theory/model to identify and to achieve the world-wide increasing requests for attaining "must-be sustainable development goals" (SDGs). Attaining such goals are necessary and urgent for transforming our fragile world into a new world where servicing all the "triple bottom line stakeholders" (economic, social and environmental stakeholders) are not only regarded as lip services but are real stakeholders which people, organisations and countries respect and hence are proud to serve, such as, the work done by Chen (2021), Reyes (2021), Frolova \& Lapina (2015). It is our hope that this projection will be a reality within the next coming 30 years.

\section{References}

Aggarwal, A., \& Zairi, M. (1997). The role of total quality management in enabling a primary health-care orientation. Total Quality Management, 8(6), 347-360. 
Álvarez-García, J., Del Río-Rama, M. D. L. C., Saraiva, M., \& Ramos-Pires, A. (2016). Dependency relationships between critical factors of quality and employee satisfaction. Total Quality Management \& Business Excellence, 27(5-6), 595-612.

Aquilani, B., Silvestri, C., Ruggieri, A., \& Gatti, C. (2017). A systematic literature review on total quality management critical success factors and the identification of new avenues of research. The TQM Journal, 29(1), 184-213.

Black, S. (1995). An empirical model for total quality management. Total Quality Management, 6(2), 149-164.

Chen, C. K., Lim, Y, \& Reyes, L. (2021) Root Cause Investigation of Climate Change: A TwoStage Interrelationship Diagram Analysis, Key Challenges and Opportunities for Quality, Sustainability and Innovation in the Fourth Industrial Revolution (volume 1), World Scientific Publisher, 379-403.

Crosby, P. B. (1979). Quality Is Free: The Art of Making Quality Certain. New York: McGrawhill.

Dahlgaard, J. J., Kristensen, K., \& Kanji, G. K. (1997). Fundamentals of Total Quality Management. Routledge.

Dahlgaard, J. J., Reyes, L., Chen, C. K., \& Dahlgaard-Park, S. M. (2019). Evolution and future of total quality management: Management control and organisational learning. Total Quality Management \& Business Excellence, 30(sup1), 1-16.

Dahlgaard-Park, S. M. (2015). The SAGE Encyclopedia of Quality and the Service Economy. SAGE Publications.

Dahlgaard-Park, S. M., Chen, C. K., Jang, J. Y., \& Dahlgaard, J. J. (2013). Diagnosing and prognosticating the quality movement-A review on the 25 years quality literature (19872011). Total Quality Management \& Business Excellence, 24(1-2), 1-18.

Dahlgaard-Park, S. M., Reyes, L., \& Chen, C. K. (2018). The evolution and convergence of total quality management and management theories. Total Quality Management \& Business Excellence, 29(9-10), 1108-1128.

Dahlgaard-Park, S. M. \& Dahlgaard, J. J. (2021). Key Challenges and Opportunities for Quality, Sustainability and Innovation in the Fourth Industrial Revolution, World Scientific Publisher.

Deming, W. E. (1982). Quality, Productivity and Competitive Position. The MIT Press.

Deming, W. E. (1986). Out of The Crisis. The MIT Press.

Dodge, H. F. \& Romig, H. G. (1941). Single sampling and double sampling inspection tables, Bell System Technical Journal, 20(1), 1-61.

Donnelly, M., \& Shiu, E. (1999). Assessing service quality and its link with value for money in a UK local authority's housing repairs service using the SERVQUAL approach. Total Quality Management, 10(4-5), 498-506.

Elshennawy, A. K., Maytubby, V. J., \& Aly, N. A. (1991). Concepts and attributes of total quality management. Total Quality Management, 2(1), 75-98.

Feigenbaum, A. V. (1961). Engineering and Management: The Technical and Managerial Field for Improving Product Quality, Including Its Reliability, and for Reducing Operating Costs and Losses. McGraw-Hill.

Frolova, I., \& Lapina, I. (2015). Integration of CSR principles in quality management. International Journal of Quality and Service Sciences, 7(2), 260-273.

Gremyr, I., \& Elg, M. (2014). A developmental view on implementation of quality management concepts. International Journal of Quality and Service Sciences, 6(2), 143-154.

Ishikawa, K. (1985). What is Total Quality Control? The Japanese Way. Prentice Hall Direct. 
Jesús Alvarez, M., Jaca, C., Viles, E., \& Colomer, A. (2012). Quality management in hotels in the basque country. International Journal of Quality and Service Sciences, 4(1), 51-60.

Islam, R., Selim, A., \& Dzuljastri, A. R. (2015). Identifying the gaps between customer expectations and perceptions on service quality dimensions of Islamic banks in Malaysia. International Journal of Quality and Service Sciences, 7(4), 424-441.

Juran, J. M. (1986). The quality trilogy. Quality Progress, 19(8), 19-24.

Kanji, G. K. (1990). Total quality management: The second industrial revolution. Total Quality Management, 1(1), 3-12.

Kim, T., \& Yoo, T. (2020). Methodology for extracting the delighter in Kano model using big data analysis. Total Quality Management \& Business Excellence, 31(5-6), 654-665.

Kumar, V., Dong-Young, K., \& Kumar, U. (2012). Quality management in research and development. International Journal of Quality and Service Sciences, 4(2), 156-174.

Lammermeyr, H. U. (1991). Human relationships - The key to total quality management. Total Quality Management, 2(2), 175-180.

Lin, B. (1995). Total quality management in health care: A survey of current practices. Total Quality Management, 6(1), 69-78.

Martensen, A., \& Grønholdt, L. (2010). Measuring and managing brand equity: A study with focus on product and service quality in banking. International Journal of Quality and Service Sciences, 2(3), 300-316.

Mauri, A., Minazzi, R., \& Muccio, S. (2013). A review of literature on the gaps model on service quality: A 3-decades period: 1985-2013. International Business Research, 6(12), 134-144.

Nadiye, O. E., \& Arani, O. M. (2019). Quality function deployment: More than a design tool. International Journal of Quality and Service Sciences, 11(2), 142-166.

Parasuraman, A., Zeithaml, V. A. \& Berry, L. L. (1985). A conceptual model of service quality and its implications for future research. Journal of Marketing, 49(4), 41-50.

Porter, M. E. (2011). Competitive Advantage of Nations: Creating and Sustaining Superior Performance. Simon and Schuster.

Pritchard, A. (1969). Statistical bibliography or bibliometrics. Journal of Documentation, 25(4), 348-349.

Radjou, N., \& Prabhu, J. (2013). Frugal Innovation: A New Business Paradigm. https://knowledge. insead.edu/innovation/frugal-innovation-a-new-business-paradigm-2375

Reyes, L., Chen, C. K., Sosa, D., \& Dahlgaard, J. J. (2021) Investigation of Industry 4.0 implementation challenges: An exploratory case study of Volkswagen, Key Challenges and Opportunities for Quality, Sustainability and Innovation in the Fourth Industrial Revolution (volume 1), World Scientific Publisher, 45-70.

Saunders, I. W., \& Preston, A. P. (1994). A model and a research agenda for total quality management. Total Quality Management, 5(4), 185-202.

Sarrico, C. S., Luís Miguel D.F. Ferreira, \& Luís Filipe, C. S. (2013). POLQUAL - measuring service quality in police traffic services. International Journal of Quality and Service Sciences, 5(3), 275-289.

Saxunova, D. (2018). Teleworking-New business paradigm. Academy of Business and Emerging Markets (ABEM) Conference, Manila, Philippines.

Schvaneveldt, S. J., Enkawa, T., \& Miyakawa, M. (1991). Consumer evaluation perspectives of service quality: Evaluation factors and two-way model of quality. Total Quality Management, 2(2), 149-162. 
Shewhart, W. A. (1924). Some applications of statistical methods to the analysis of physical and engineering data. Bell System Technical Journal, 3(1), 43-87.

Shewhart, W. A. (1931). Economic Control of Quality of Manufactured Product. Macmillan And Co Ltd, London.

Sohal, A. S. (1994). Managing service quality: Developing a vision and a strategy. Total Quality Management, 5(6), 367-374.

Tontini, G. (2007). Integrating the Kano model and QFD for designing new products. Total Quality Management, 18(6), 599-612.

Trenchard, P., \& Dixon, R. (1999). Total quality management in non-profit secondary health care. Total Quality Management, 10(7), 979-986.

Van Eck, N., \& Waltman, L. (2010). Software survey: VOSviewer, a computer program for bibliometric mapping. Scientometrics, 84(2), 523-538.

Van Eck, N., \& Waltman, L. (2013). VOSviewer manual. Leiden: Univeristeit Leiden, 1(1), 153.

Vargo, S. L \& Lusch, R. (2008). Service-dominant logic: Continuing the evolution. Journal of the Academy of Marketing Science, 36(1), 1-10.

Wood, S. (1997). The quest for service excellence. Total Quality Management, 8(2-3), 328-331.

Wynne, R. M., \& Lancaster, J. (1992). The importance of understanding the concepts of total quality management and the consequent training needs. Total Quality Management, 3(1), 1930.

Yang, C. C. (2017). The evolution of quality concepts and the related quality management. In L. Kounis (Ed.), Quality Control and Assurance-An Ancient Greek Term Re-mastered (pp. 319). Intech Open.

Yang, C., Lan, S., \& Huang, G. Q. (2019). Revenue sharing model in New Hong Kong's warehousing business paradigm. Journal of Ambient Intelligence and Humanized Computing, $10(3), 883-892$. 